\title{
Estado subsidiario: límites y proyecciones de la democracia territorial en Chile
}

\author{
Emmanuel Farías Carrión ${ }^{1}$ y \\ Juan José Moreno Figueras ${ }^{2}$
}

Fecha de recepción: 7 de octubre de 2015

Fecha de aprobación: 28 de enero de 2016

\begin{abstract}
Resumen
Las claves políticas con las que convive la ciudadanía en Chile son expuestas en este documento como un proceso institucional de un profundo espíritu conservador: Estado subsidiario, democracia protegida y el gasto social focalizado como medio de inversión es lo que caracterizaría la esencia del sistema político hoy. El documento identifica la desigualdad entre los espacios locales y su relación de dependencia como consecuencia de la administración del Estado subsidiario, y su pretensión de desarrollar una fórmula neoliberal para la satisfacción de necesidades individuales. Esta fórmula cobra relevancia cuando se observa a los espacios locales, dado que la misma lógica opera para estos, dejando en evidencia que la capacidad de desarrollo de cada comuna está determinada por sus propios atributos y competitividad, en un contexto de mercado desregulado y en ausencia de planificación territorial a escala regional o metropolitana. Es en este contexto que la democracia local se ve limitada por su falta de comprensión de un territorio mayor y de la ciudad como un todo, siendo ineficaz para una distribución de poder más profunda.
\end{abstract}

Palabras clave: Estado subsidiario, territorio, democracia, espacio locales.

\section{Subsidiary State: limits and projections of the territorial democracy in Chile}

\begin{abstract}
This document presents the political clues coexisting in Chilean citizenship as an institutional process of deep conservatism: subsidiary State, protected democracy and targeted social spending as a means of investment characterize
\end{abstract}

Sociólogo, Universidad Católica Silva Henríquez, diplomado en Gobierno y Gestión Pública, Universidad Alberto Hurtado; candidato a Magíster en Ciencias Sociales, mención en Sociología de la Modernización, Universidad de Chile. Contacto: emmanuel.fariascarrion@gmail.com

2 Licenciado en Arquitectura, Pontificia Universidad Católica de Chile; cursando Magíster en Desarrollo Urbano, Pontificia Universidad Católica de Chile. Contacto: jjmoreno@uc.cl 
the essence of the political system today. The document identifies inequalities among areas and their dependence resulting from the subsidiary State administration and its attempt to develop a neoliberal formula for the satisfaction of individual needs. This formula becomes important when viewed in local areas, since the same logic applies to them, making it clear that the development capacity of each municipality is determined by its own attributes and competitiveness in a deregulated market context and in the absence of spatial planning at regional or metropolitan scale. In this context, local democracy is limited by its lack of compression of a broader territory and the city as a whole, being ineffective for achieving a deeper distribution of powers.

Keywords: Subsidiary State, territory, democracy, local space.

\title{
Estado subsidiário: limites e projeções da democracia territorial no Chile
}

\begin{abstract}
Resumo
As chaves políticas com as quais convive a cidadania no Chile são apresentadas neste documento como um processo institucional de um profundo espirito conservador: Estado subsidiário, democracia protegida e gasto social direcionado como meio de investimento é o que caracterizaria a essência do sistema político hoje. $\mathrm{O}$ documento identifica a desigualdade entre os espaços locais e a sua relação de dependência como resultado da administração do Estado subsidiário, e sua pretensão de desenvolver uma fórmula neoliberal para a satisfação das necessidades individuais. Esta fórmula torna-se importante quando se observa aos espaços locais, dado que a mesma lógica opera para estes, deixando em evidencia que a capacidade de desenvolvimento de cada município é determinada por seus próprios atributos e competitividade num contexto de mercado desregulamentado e na ausência de planejamento territorial à escala regional ou metropolitana. É neste contexto que a democracia local é limitada pela sua falta de compressão de um território maior e da cidade como um todo, sendo ineficaz para uma distribuição de poder mais profunda.
\end{abstract}

Palavras-chave: Estado subsidiário, território, democracia, espaço local.

\section{Introducción}

A continuación se presenta un argumento que tiene como pretensión comprender la manera como se administra el desarrollo del Estado nación. Para esto se verán sus dimensiones teórico-políticas para el caso chileno. En la primera parte se observará al Estado subsidiario y su relación con la figura de ciudadanía, la cual se efectúa mediante una serie de procesos caracterizados por la violencia burguesa desde los sectores conservadores del país, y así observar cómo se destinan recursos jurídico-políticos 
para el control del carácter subjetivo de la ciudadanía, mediante la formación de una estructura de expectativas predeterminadas por un marco jurídico político. La segunda parte del documento toma un carácter más político e identificará la relación del Estado subsidiario con el territorio, pero comprendido en su contexto, identificando la focalización como medio de inversión social para la organización y legitimación del modelo, entendiendo así que las consecuencias de dicha fórmula política han dejado a los actores sociales locales sin un espacio de incidencia política y social relevante.

La discusión necesita de claridad: ¿cuáles son las responsabilidades políticas de los sectores comprometidos en la administración del Estado con el fracaso neoliberal? ¿Existe información en la comunicación política? O, ¿de qué forma el Estado subsidiario construye expectativas colectivas? Este documento busca legibilidad en cuanto al funcionamiento de la administración estatal, en la cual la desvinculación con los derechos de ciudadanía sería el medio para la promoción de las competencias individuales. El éxito de algunas de estas competencias en personas en desmedro de otras es lo que obligaría un compromiso de solidaridad. Diremos, para efectos del documento, que es una forma "curiosa" de comprender el desarrollo colectivo y, más que acciones de buena fe, nos encontramos con una mirada de violencia política.

\section{Primera parte: reflexiones teóricas}

¿Qué significa asumir una posición teórica cuando se analiza la conexión entre el gobierno central y espacios locales? O, ¿qué certeza pueden dar conceptualizaciones políticas al momento de pensar un espacio local, su desarrollo y democratización? El tema de fondo siempre será la relación entre lo empírico y lo teórico. Se asumirá que una posición teórica busca aumentar el nivel de tensión en un argumento político, esto si se pretende una reflexión sobre las tácticas y estrategias de intervención para que estas sean lo más exitosas posibles. Lo político no será entendi- 
do exclusivamente como un instrumento de promesas para la obtención de votos, como muchos creen, sino un sistema relacionado directamente con el poder para administrar su distribución y ejecución. Es así como este documento busca problematizar la situación del Estado subsidiario chileno con las proyecciones democratizadoras a las que se enfrenta el territorio.

\section{Hacia una descripción del Estado subsidiario}

El Estado se convierte en el centro gravitacional de la organización del sistema político; municipios, políticas públicas, territorios, comunidad política, partidos políticos, movimientos de protestas, constituciones, procedimientos, leyes, etc., son los elementos que giran en torno a él. Al mismo tiempo, el Estado posee una multiplicidad de lecturas. En un intento de interpretación -de código marxista- se dirá que las personas de la sociedad experimentarían constantes reproducciones de capital, ya sean económicas, culturales y / o de carácter social. Para Bourdieu (2000) "el capital es trabajo acumulado, bien en forma interiorizada o incorporada. Cuando agentes individuales o grupos se apropian de capital, privada o exclusivamente, posibilitan también, gracias a ello, la apropiación de energía social en forma de trabajo...". No es posible dar cuenta de la estructura y funcionamiento social sin introducir un nuevo concepto de capital en todas sus manifestaciones, ya que el concepto clásico de "capital" reduce el universo de las relaciones sociales de intercambio al simple intercambio de mercancía. Las reproducciones de capital mencionadas anteriormente generarían una confrontación de intereses entre sectores o clases sociales. Esto se traduciría, para el caso chileno, como aquel momento de disputa por la organización de la sociedad que será superada por la obtención del Estado y su capital; así el Estado se puede convertir en una figura de control o de liberación dependiendo de quién la domine -desde la teoría-. Mediante esto es posible definir el "horizonte de la sociedad" y su determinación histórica. Hasta el momento, el Estado ha sido consecuencia del dominio burgués (en la modernidad esto se de- 
muestra desde el colonialismo hasta la dependencia latinoamericana con la participación en la economía mundial).

Desde el ejercicio de la interpretación, se utilizarán líneas sobre cómo se debe reconocer el Estado para abrirnos hacia una discusión política compleja, ahora en códigos contractualistas: 1) la soberanía reside esencialmente en la nación, y se ejerce por el pueblo; 2) la ley es la voluntad del soberano y el soberano es el pueblo, son algunas de las "leyes políticas" que fundamentan la filosofía política moderna y, al mismo tiempo, serían la fuente de operación de la democracia representativa. Nuevamente esta multiplicidad de lecturas e interpretaciones sobre qué entender por "Estado" (Offe, 1988) expondría una discusión pública sobre cuáles deberían ser las pretensiones políticas para la dirección del Estado nación. Existiría una ciencia social liberal contra una interpretación más crítica, que disputaría la tensión del paradigma político. La primera habla sobre sus operaciones y procedimientos desde una línea más sistémica o descriptiva (Luhmann, 2005), mientras que la más crítica discutiría sobre el espíritu burgués que envuelve al Estado moderno, este último como un logro de la violencia física sobre la servidumbre. La obtención del Estado sería una de las etapas para la emancipación en un sujeto moderno (Hegel, 2009; Lukacs, 2009; Pérez, 2010).

Toda teoría política que merezca ese nombre debe responder a dos cuestiones. En primer lugar ¿cuál es la forma deseable para organizar la sociedad y el Estado, y cómo podemos demostrar que será "practicable" o coherente con nuestras suposiciones normativas y fácticas básicas sobre la vida social? Este es el problema de definir un modelo o meta coherente de transformación. En segundo lugar, ¿cómo llegar hasta allí? Este es el problema de identificar las fuerzas y estrategias dinámicas que suscitarían la transformación. (Offe, 1988, p. 141).

Después de decir que el Estado se enfrenta a interpretaciones morales, intelectuales o ideológicas, se dirá que la instauración 
del Estado subsidiario no fue una consecuencia de la evolución progresiva de un debate público. Detrás del Estado subsidiario chileno se encuentra una composición de facto y violencia burguesa. Posterior a esta fecha clave de la historia política de Chile en el siglo XX, el Estado comienza a experimentar una mutación respecto de sus instituciones públicas y su espíritu político, dejando la posibilidad de crecimiento material y cultural a las aptitudes y competencias que tenga una persona, aparte de su contexto social. Existiría -desde el neoliberalismo- una apuesta por la desvinculación del Estado con los deberes de ciudadanía, y al traspaso de derechos sociales como salud, vivienda y educación hacia el sector privado. La cuestión sería la siguiente: ¿cuáles son los criterios de asignación de recursos de una política pública? O, ¿cómo enfrenta el Estado la relación con sus ciudadanos? Para Faletto (2007), estas preguntas obligarían al Estado a dejar en evidencia los intereses de representación. Es decir, si un Estado reconoce altos niveles de desigualdad -como lo han hecho los países neoliberalizados, ergo el caso chileno-, este debería orientar su desarrollo en la mejora de distribución de los ingresos. En la misma línea, Faletto (2007) dirá que asignar este criterio de distribución solo al sistema de mercado aumentaría los niveles de desigualdad. Crecimiento/igualdad se convertirían en elementos en contradicción; el primero estaría en desmedro del segundo, producto de un principio de acumulación, mientras que el segundo interrumpiría al crecimiento por el exceso de tributo. Esta apuesta "neoliberal", proveniente de las sociedades de mercado, buscaría mejorar sus niveles de producción a partir del "sueño americano". El debate sobre sociedad y Estado en Chile se cancela por el pacto político de la Constitución de 1980.

\section{Descripción del Estado subsidiario en Chile}

Si queremos una democracia auténticamente libertaria, y no estatista o socializante, es menester arraigar en los chilenos el ejercicio de las libertades económico-sociales, identificadas con los derechos cotidianos que más gravi- 
tan en la efectiva decisión de cada persona respecto de su destino personal y familiar. (Guzmán, 1982, p. 7).

La figura subsidiaria en Chile se manifiesta en el Estado desde la Constitución de 1980. Ella consagra la subsidiaridad del Estado como eje articulador del nuevo modelo de desarrollo chileno, en el que los derechos sociales se transforman en bienes de consumo y el Estado se desentiende de sus responsabilidades históricas. Ejemplo de esto es la Ley Orgánica Constitucional de Enseñanza: "El Estado tiene, asimismo, el deber de resguardar especialmente la libertad de enseñanza" (Ley $\left.N^{\circ} 18.962,1990\right)$. Esto demuestra la arbitrariedad moral de dicha disposición constitucional como mecanismo de selección. Al mismo tiempo, la Constitución política de 1980 entrega la responsabilidad a los padres de elegir el establecimiento educacional para sus hijos, dejando de lado la responsabilidad del Estado: "Los padres tienen el derecho preferente y el deber de educar a sus hijos. Corresponderá al Estado otorgar protección al ejercicio de este derecho" (art. 19 inc. 10). Esta es una muestra taxativa del imperativo ideológico de la burguesía y la subsidiaridad, es decir, después de la implementación del modelo, mediante la violencia física y la articulación en redes de coordinación para fines de consumo, está la ejecución legislativa del funcionamiento jurídico del Estado, la cual compromete todo el accionar político de una comunidad, amparada en la libertad de enseñanza como un instrumento de responsabilidad de las personas más que un deber asegurado por derechos.

En lo práctico y para efectos del caso, se entenderá que el Estado subsidiario en Chile operaría como una camisa de fuerza para el desarrollo democratizador chileno. Sin bien los resultados han sido: disminución en los niveles de pobreza desde el 80 hasta la fecha, una inflación regulada y el consumo como fiesta de las relaciones deseo/producto, esto no asegura la satisfacción de los derechos que debe garantizar un Estado nación en su territorio. En sí, el Estado subsidiario permite instancias de participación con los espacios locales -comunas, regiones y ciudades-, pero en forma cuestionable. La participación de las comunas, como 
veremos más adelante, es caracterizada por el capital cultural y financiero que produzca cada espacio local; la participación no solo se evalúa desde la elección de autoridades políticas, también es un momento en el cual la ciudadanía se vincula con el Estado central, municipios, servicios públicos y gasto en provisiones públicas.

Anteriormente se anunció que el Estado subsidiario genera una relación con el ciudadano que se caracteriza por reconocer las competencias que tenga cada individuo. Aquel dueño de competencias será quien optará a una vida de libertades. Se puede observar en el liberalismo de Rawls (2012) que esta -la competencia- sería una condición sine qua non del ser humano: el hecho de vivir con un grupo de personas obligaría a aquellos privilegiados a una acción solidaria con los individuos menos afortunados. La tesis que se esgrime a continuación busca generar una tensión con el paradigma neoliberal chileno, diciendo que la relación no tan solo se vincula con el ciudadano, la persona o el habitante de un territorio, sino con sus espacios locales y territoriales; esto dificulta la convivencia con un espacio social común, entendido como ciudad. La aproximación que tenemos a la ciudad no la comprende como un producto sino que como un proceso, la ciudad no como una etiqueta político-administrativa que depende del número de habitantes, sino que como un espacio social. Lefebvre plantea en su obra El derecho a la ciudad que no es una ciudad en absoluto, sino toda una sociedad, donde lo "urbano" no es más que una sinécdoque y una metáfora. Para el autor no es el derecho a la ciudad existente, es el derecho a una ciudad futura, la que no tiene que ser una ciudad como convencionalmente la entendemos, sino que un lugar en una sociedad urbana en donde la distinción jerárquica entre el campo y la ciudad ha desaparecido (Lefebvre, 1968). La configuración de neoliberalismo subsidiario se introduce también en la planificación no solo política, sino también urbana, generando espacios locales -comunas-, con una evidente dependencia de las lógicas de desarrollo subsidiario y reduciendo la participación comunal. 
La proyección histórica del Estado subsidiario se sostiene en la elite política y en disposiciones constitucionales, la construcción de una figura de ciudadanía y espacios locales desiguales y dependientes. Si bien discutir sobre el imaginario de la elite puede ser atractivo, este documento la presenta tan solo como una red institucionalizada de partidos caracterizados por su hegemonía en la apropiación de capital. Dicha caracterización de partidos para el caso chileno se comprende junto a la derecha golpista, como una red de partidos que tiene como pretensión agenciar un discurso progresista. Esto fue traducido por la Concertación de Partidos por la Democracia en una fórmula política de centroizquierda, de espíritu socialdemócrata, pero termina siendo un grupo de partidos políticos que opta por un giro institucional hacia el neoliberalismo, convirtiéndose en un bloque que administra la herencia posdictadura. En síntesis, el Estado subsidiario chileno se reconoce como un Estado fundado en principios de acumulación, desvinculaciones con derechos sociales y con una fuerte creencia en la doctrina social de la iglesia, que es la reacción política o la alternativa al choque ideológico de corrientes fascistas o marxistas de mediados del siglo XX. Lo dicho por Guzmán y su constitución es que existiría un pluralismo ideológico que debe ser reconocido y respetado por el Estado y la carta constitucional sería la base de convivencia a la que se sujetarían las personas. Para legitimar este pluralismo -entendido como una multiplicidad de libertades individuales- es necesaria la consagración de un régimen democrático binominal en sus cámaras, con el fin de resguardar lo que se llamó "democracia protegida", la que tiene como característica identificar y rechazar alteraciones en el sistema de organización política. Esta idea de democracia busca anular insurrecciones populares que puedan traducirse en "populismos demagógicos" (Guzmán, 1982). Los constitucionalistas de la época -comisión Ortúzar- identifican como principal problema las fuerzas populares de vanguardias políticas de izquierda.

Sería absurdo no considerar la propuesta ideológica en el itinerario político chileno. El Estado subsidiario se transforma así en 
una apuesta por la convivencia humana. La experiencia política chilena evidencia que lo vivido desde los gobiernos de la Concertación es la estabilidad del modelo subsidiario. Chile lo experimenta desde las responsabilidades del Estado hasta las expectativas de la Constitución con la ciudadanía. En el debate constitucional, la comisión Ortúzar buscó definir qué se entendería por hombre: "toda la doctrina sobre el Estado, la soberanía, la democracia, el gobierno y los derechos individuales y sociales, descansa en una concepción cristiana del hombre; en el reconocimiento de que el hombre encierra valores espirituales que están más allá del ordenamiento jurídico positivo" (Actas oficiales de la Constitución, octubre de 1973). Esto no solo demuestra el interés en desvincular los derechos sociales sino también en definir un perfil ciudadano, el cual debe cumplir un consenso mínimo de convivencia, definido por la capacidad estructurante del Estado subsidiario chileno. La subsidiaridad del Estado se adscribe como una filosofía del todo, al contemplar no solo relaciones en el nivel de subsistemas sino también la condición de posibilidad a la que se enfrentan las personas con sus expectativas de vida. La subsidiaridad aseguraría que todas aquellas posibilidades de selección están previamente definidas por competencias naturales de cada persona.

\section{Estado subsidiario, democracia y descentralización}

El Estado subsidiario en Chile se comprenderá, para efectos de este argumento, como una (1) línea evolutiva interrumpida, o sea, aquel momento histórico que experimenta la anulación de la soberanía del pueblo mediante la violencia burguesa de 1973. Otra (2) línea constitucional, que reformula las responsabilidades del Estado con derechos universales y los reemplaza por la libertad individual de las personas. Y una (3) línea política, que reconoce que el Estado subsidiario tiene una pretensión en el control de la esencia subjetiva de las personas. Estas convivirían en una comunidad que busca una pluralidad ideológica, cuyo fin es definir las orientaciones del Estado subsidiario en un plano de control sociopolítico. 
La tesis de este artículo es que el Estado Subsidiario aparece cuando los espacios locales -las comunas- no se reconocen entre sí como partícipes de un campo social igualitario -ciudad, regiones, Estados nación-. Frente a esto último, Iván Finot (2002; 2005), desde la teoría de la descentralización, dirá que la administración subnacional -o espacios locales, como se ha definido al interior de este documento- busca traspasar parte de la provisión de bienes públicos hacia procesos democráticos subnacionales, para generar vinculaciones cooperativas entre las organizaciones de la sociedad: gobierno central, municipios, organizaciones sociales, sector privado, etc., generando mayores niveles de democratización e identidad: "El sujeto de la descentralización política, entonces, deberían ser las comunidades subnacionales, mientras que sus respectivos aparatos gubernamentales no serían sino instrumentos para adoptar y ejecutar esas decisiones" (Finot, 2002, p. 143). La descentralización busca apropiarse del proceso de gasto social. Esto se produce en la medida en que existan espacios locales organizados en torno a una demanda común; así se facilita una relación de pertenencia con aquella instancia de provisión. Para Finot el rol de los municipios sería fundamental, ya que "tendrían la responsabilidad del ordenamiento territorial y de la concentración del desarrollo económico territorial" (2002, p. 145), formatos con los cuales opera Brasil (municipios) y Argentina (gobiernos provinciales).

El punto de fondo de esta teoría sería la descentralización del aparato político administrativo (gobierno central), la cual permite a las administraciones subnacionales (espacios locales, comunidades) estimular relaciones de autonomía para mejorar relaciones de competencia.

En efecto, se ha llegado a consenso en que la competitividad depende no solamente de las empresas, de los equilibrios macroeconómicos y de políticas nacionales activas, sino de la capacidad de cada localidad para encarar su propio desarrollo a través de procesos de concentración público-social-privado. Y para esto es indis- 
pensable que las localidades cuenten con su autonomía.

(Finot, 2005, p. 30).

Sin perder el norte, se dirá que esta es la característica propia del Estado subsidiario, por tanto se dirá que hay dos ideas en Finot y la descentralización. Parafraseando el primer argumento dice: es necesario un espacio comunal autónomo que asuma responsabilidades con su propio desarrollo para profundizar mayores grados de democratización; esta responsabilidad permitirá participar en proceso de asignación de provisiones para cada comuna. Lo segundo tiene que ver con sus conclusiones: es necesaria autonomía en la dimensión subnacional para estimular relaciones de competencia. Este documento opta por sus argumentos más que por sus conclusiones.

La descentralización sería entendida entonces con un fuerte componente económico, en donde las asignaciones materiales, ya sean financieras o de bienes públicos, deben ser consideradas como parte de las transferencias que se realizan a los espacios locales para fortalecer su autonomía. Es importante esta consideración si queremos observar el desempeño del Estado subsidiario en relación con la democracia. El discurso descentralizador del Estado subsidiario chileno apuesta por la autonomía y el empoderamiento local, transfiriendo responsabilidad que históricamente había sido competencia del Estado. Una pregunta que surge en cuanto a las asignaciones materiales de las que hablaba Finot es la siguiente: el Estado chileno, ¿se ha preocupado de traspasar los recursos a las comunas que históricamente invertía cuando los servicios públicos como educación y salud estaban bajo su responsabilidad? En relación con este cuestionamiento, vemos que el Estado no ha transferido los recursos que invertía en asegurar estos derechos sociales. La municipalización de los servicios significó una fuerte diferencia de su calidad, dependiendo de los recursos que cada municipio tuviera.

Se puede decir entonces que la descentralización que ha propuesto el Estado subsidiario en Chile no ha tenido la preocupa- 
ción de generar un traspaso significativo en la provisión de bienes públicos hacia procesos democráticos subnacionales. Por el contrario, el razonamiento neoliberal ha dejado operar una lógica de competencia entre comunas en el cual su desarrollo económico y cultural dependerá de manera casi exclusiva de sus propios atributos y competitividad. El déficit presupuestario que presentan los municipios menos acomodados y las desigualdades entre los diferentes espacios locales generan municipios de primera y segunda categoría al momento de definir el territorio: solo algunos ciudadanos son considerados al momento de la producción del espacio. El concepto "producción del espacio" viene del aporte teórico de Lefevbre (1974), haciendo referencia al espacio social y no exclusivamente a la producción de bienes o mercancías. Lo anterior se expresa en un proceso muy poco democrático en la constitución de nuestras ciudades.

Por tanto "democracia" se comprenderá como la evolución del régimen autoritario, totalitario, absolutista o monárquico. Este régimen es el espacio de coordinación del sistema político, adviene como una unidad de sistemas complejos que se comunican para conformar un sistema socialmente diferenciado. Helmut Wilke dirá que la democracia, más que un principio de dominación, es la autoorganización de sistemas socialmente complejos (2006), por ejemplo, sistema político, sistema derecho, sistema económico, en el que cada uno tiene un contenido informativo distinto al otro. La democracia se incrusta al interior de un tipo de Estado, esto definirá el tipo de democracia. Si en Chile el Estado nación ha sido definido por su subsidiaridad, la democracia se comprenderá por su principio de protección, que es la anulación de representación de sectores populares. La lógica de la democracia protegida chilena es instaurada por el régimen militar, y ella no permite una participación de partidos disidentes al gobierno. El trabajo a continuación es identificar cómo la distribución de poder en el espacio metropolitano es consecuencia de esta democracia protegida y la necesidad de buscar nuevas definiciones sobre democracia en el territorio. 


\section{Segunda parte: Política local y planificación}

Este documento expone la justificación entre teoría -aquello que se piensa- y lo político -aquello que se observa y planifica-. Se comprenderá cómo el Estado se relaciona con sus territorios en una dimensión democrática, siendo capaz de asignar recursos y construir condiciones de participación con sus espacios públicos. El Estado es una composición teórica que sin el territorio no podría cumplir su condición normativa necesaria para cualquier proyecto político democratizador. Por esto se muestran indicadores de calidad de vida, los cuales demuestran el fracaso administrativo de la subsidiaridad como modelo de desarrollo neoliberal.

\section{Estado y territorio: lógicas de dependencia}

El diseño del Estado subsidiario determina las relaciones que se establecen entre la centralidad del aparato público y sus distintos niveles de funcionamiento. Así, dicha visión tiene una comprensión total, permeando todos los niveles institucionales. Esta comprensión no solo determina las directrices generales del modo de desarrollo neoliberal chileno, condicionado por el Estado subsidiario, sino que también contempla una forma de reproducción multiescalar, operando en los diferentes espacios -nacional, regional, provincial, comunal y barrial- del territorio chileno. Para entender el concepto territorio, nos aproximaremos desde el enfoque territorialista, que se plantea como una construcción histórica y en constante transformación; es el resultado de la interacción prolongada entre las personas y su ambiente, que genera una estructura de larga duración (Magnaghi, 2011).

La hechura del Estado subsidiario mantiene con los espacios locales lógicas similares a las que establece con la ciudadanía, dejando las posibilidades de desarrollo material y cultural a los atributos y nivel de competitividad que tengan las diferentes comunas, sin considerar el contexto social en que se encuentran, dejando operar con muy pocas restricciones al mercado. Esta li- 
mitante estratégica ha imposibilitado una asignación mayor de recursos desde el Estado, lo que ha obligado a usar las políticas de focalización como única forma de inversión posible. Raczynski las describe como aquellas que:

(...) se proponen beneficiar únicamente a sectores poblacionales que se hallan por debajo de cierto umbral de pobreza o riesgo social. Frecuentemente el criterio categorial se entrecruza con el de pobreza en programas específicos: programas de capacitación para jóvenes pertenecientes a hogares de escasos recursos, programas de alimentación complementaria para madres embarazadas y niños menores de 6 años con desnutrición, programas de mejoramiento de la calidad de la educación básica que priorizan sus acciones en las escuelas con un bajo nivel de aprendizaje. De esta forma, se hace una distinción entre políticas selectivas que benefician a todas las embarazadas, menores de 6 años, jóvenes, etc., y políticas selectivas focalizadas dirigidas a los estratos más carenciados o débiles al interior de dichos segmentos (Raczynski, 1995, p. 218).

Las primeras consecuencias que podemos asociar a esto son las formas precarias en que el Estado asume sus compromisos históricos en derechos sociales, tales como educación, salud, vivienda, derecho al trabajo, entre otros, como se describió. Sin embargo, el actual diseño del Estado tiene también consecuencias en los espacios locales. La reducción del Estado, la falta de recursos económicos y la poca iniciativa que este tiene se traducen en un apoyo muy débil desde los niveles centrales o intermedios a la escala local o comunal. Las consecuencias son condiciones radicalmente diversas entre las diferentes comunas que componen la división político-administrativa en el territorio. Para bajar a casos concretos, nos referiremos a la situación que se genera en la Región Metropolitana (RM) de Santiago, 
específicamente entre las comunas del Área Metropolitana de Santiago (AMS).

La razón por la que se elige esta región es porque es donde existe más información estadística disponible para generar análisis en función de los planteamientos teóricos aquí señalados. La necesidad de generar indicadores multidimensionales y con una correspondencia territorial es algo reciente, por lo tanto su existencia también restringía fuertemente los espacios disponibles para trabajar este artículo. Por otro lado, las grandes metrópolis son espacios que muestran de manera mucho más clara las considerables desigualdades de nuestra forma de desarrollo, siendo el espacio de operación central -al menos en el nivel nacionaldel capital financiero para desplegarse en el territorio (Sassen, 1999). Es en territorios como el AMS donde las desigualdades del sistema neoliberal, bajo su lógica subsidiaria, quedan totalmente desnudadas. Es allí donde pueden llegar a compartir el mismo espacio los grupos más ricos y los más pobres de nuestro país. El AMS está conformada por 34 comunas de las 52 que conforman la Región Metropolitana (RM), contando con una población de 5,5 millones de habitantes, más del $90 \%$ de la población de la $\mathrm{RM}^{3}$.

\footnotetext{
3 No existen consensos absolutos al momento de definir las áreas metropolitanas, ni siquiera cuando están definidas institucionalmente con sus respectivas autoridades, ya que, regularmente, sus funcionamientos y dinámicas se extienden a territorios mayores de los que formalmente establecen sus divisiones político-administrativas. En este caso, ocuparemos la descripción de AMS utilizada en el trabajo de Arturo Orellana La gobernabilidad metropolitana de Santiago: la dispar relación de poder de los municipios.
} 


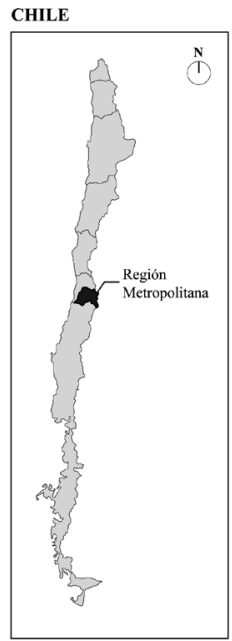

\section{REGIÓN METROPOLITANA}

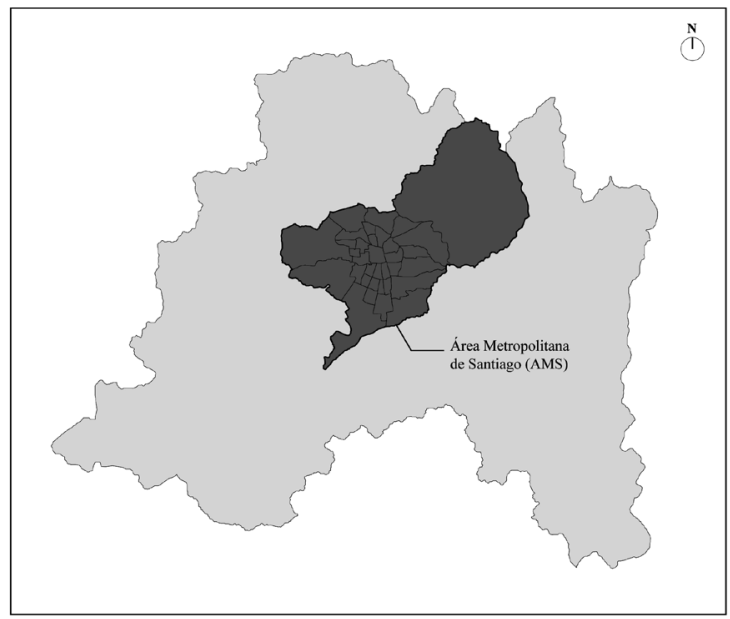

Fuente: Elaboración propia.

\section{ÁREA METROPOLITANA DE SANTIAGO (AMS)}

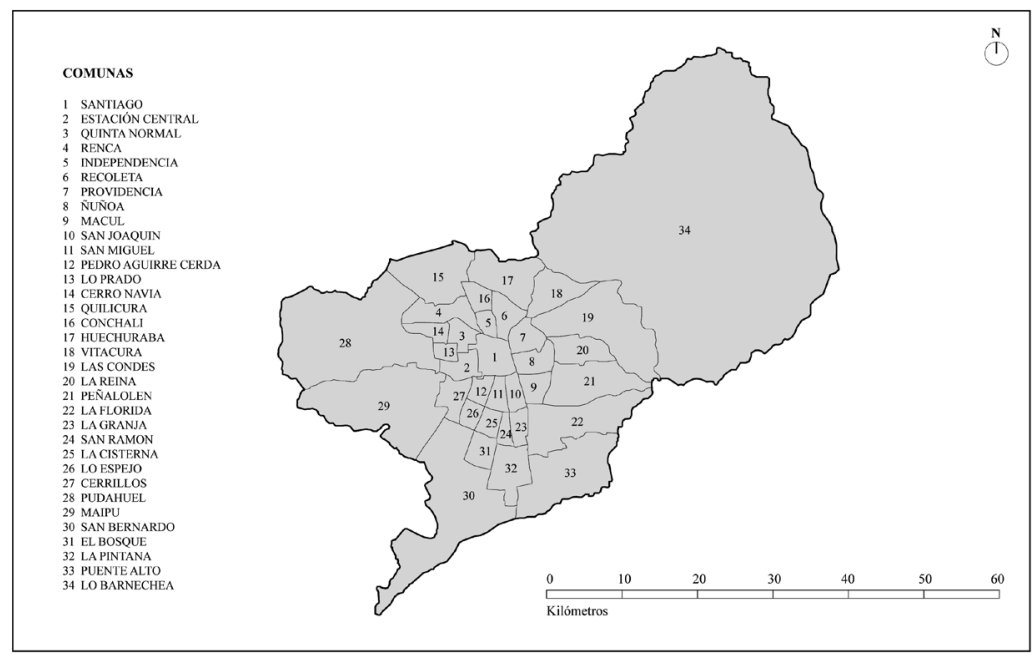

Fuente: Elaboración propia.

Por tanto, es necesario saber con precisión las diferencias de recursos culturales y materiales que existen entre las comunas que componen el Área Metropolitana de Santiago. Orellana (2009) propone una metodología para la construcción de perfiles socioterritoriales de los municipios de la Región Metropolitana. Estos 
se definen con base en los coeficientes obtenidos por la elección de cuatro variables que el autor selecciona ${ }^{4}$. Este trabajo arroja dos polos totalmente opuestos; por un lado, un alto nivel educacional donde habitan las clases dirigentes, caracterizadas por municipios con abundantes recursos, y, en el otro extremo, municipios con alta presencia de pobreza, insuficiencia presupuestaria y totalmente apartados de los avances del desarrollo de la ciudad global. Es esto lo que caracterizaría las lógicas de dependencia del Estado subsidiario en Chile e impide una incidencia efectiva de las comunas en la producción del espacio metropolitano.

\section{ÁREA METROPOLITANA DE SANTIAGO (AMS)}

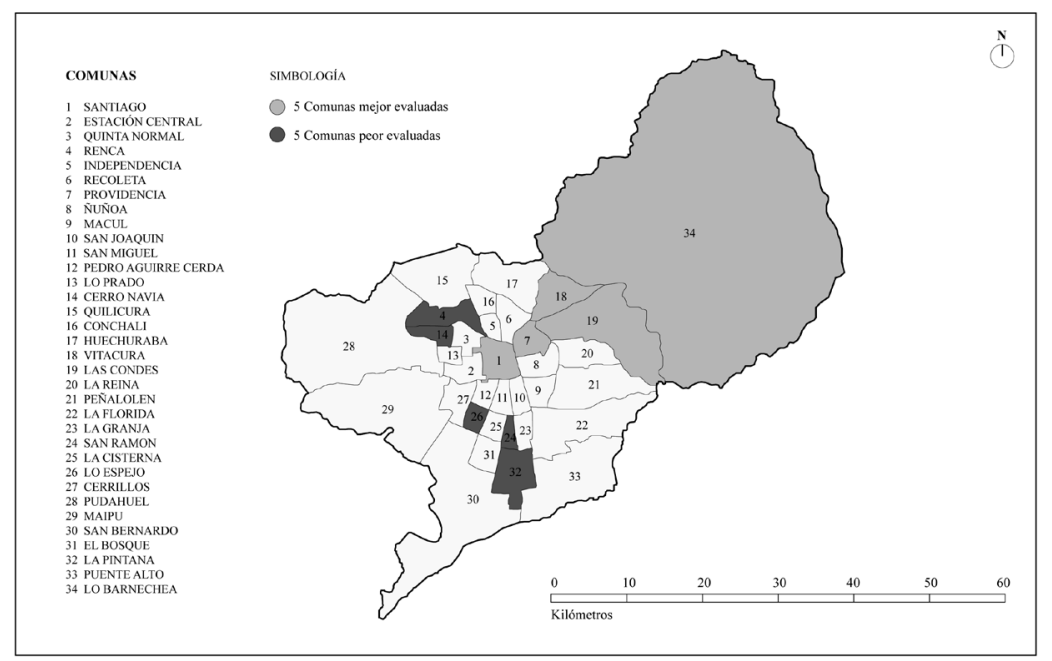

Fuente: Elaboración propia.

Esta realidad queda de manifiesto cuando comparamos la dependencia de las diferentes comunas al Fondo Común Municipal $(\mathrm{FCM})^{5}$. Mientras las cinco comunas que lideran el ranking tienen

\footnotetext{
4 El método considera el peso de la población total del municipio dentro del total del AMS, como punto base de referencia que permita posteriormente la comparación intermunicipal entre factores, ocupando la siguiente fórmula para el cálculo del coeficiente: Coeficiente $=(\%$ factor $-\%$ población $) /(\%$ factor $+\%$ población $)$.

5 "El Fondo Común Municipal constituye la principal fuente de financiamiento para los municipios chilenos. La propia Constitución Política chilena, en su Artículo
} 
una dependencia menor a un 10\% del FCM, las cinco últimas tienen un promedio de dependencia de un $50 \%$. Las primeras concentran el $42 \%$ del PIB del AMS, mientras las segundas se quedan con el $8 \%$. El presente argumento establece como hipótesis que las desigualdades generadas en las comunas tienen un vínculo directo con el diseño del Estado subsidiario, ya que, al ser tan reducido el presupuesto que proviene desde instancias centrales o regionales, las municipalidades dependerán de sus propios atributos locales para generar recursos y, en definitiva, llevar a cabo un proyecto local con ciertos grados de autonomía; es esto lo que hace patente estas lógicas de dependencia. Mientras algunas comunas generan recursos por sus propias actividades económicas, dependiendo de manera muy poco significativa de otras fuentes de financiamiento, la gran mayoría no tiene esta posibilidad.

Lo anterior tiene directa relación con la distribución del poder existente en el AMS. Las lógicas de dependencia generadas imposibilitan el empoderamiento territorial de las comunas más pobres, ya que su espectro de autonomía se ve dramáticamente reducido por la inevitable dependencia económica que condiciona su relación con el Estado. Las municipalidades más ricas pueden entablar relaciones de igual a igual con los gobiernos re-

122, lo define como un 'mecanismo de redistribución solidaria de los ingresos propios entre las municipalidades del país'. Asimismo, la Ley No 18.695 , Orgánica Constitucional de Municipalidades, a través de su Artículo 14, le confiere la función de 'garantizar el cumplimiento de los fines de las municipalidades y su adecuado funcionamiento'.

Si bien todas las municipalidades del país reciben recursos por este instrumento, las comunas que tienen mayores ingresos aportan mayores flujos monetarios de los que perciben. De esta manera, las cuatro comunas de mayor capacidad económica del país (Santiago, Providencia, Las Condes y Vitacura) tienen un aporte diferenciado al Fondo Común Municipal, el cual les obliga a contribuir al FCM con parte importante de la recaudación por patentes comerciales (el resto de las comunas no aporta por este concepto) y, a su vez, aportar un monto mayor de la recaudación de su impuesto territorial" (Subsecretaría de Desarrollo Regional y Administrativo, 2009).

Las cinco primeras comunas del rankig son Providencia, Vitacura, Las Condes, Lo Barnechea y Santiago, mientras que las cinco últimas son La Pintana, Cerro Navia, Lo Espejo, San Ramón y Renca; véase el trabajo de Arturo Orellana (2009), La gobernabilidad metropolitana de Santiago: la dispar relación de poder de los municipios. 
gionales o las diferentes carteras del Estado. Las intervenciones urbanas de carácter metropolitano deben ser consensuadas con las autoridades que representan a los territorios más favorecidos. Por otro lado, los ediles de las comunas más pobres no tienen alternativas a la hora de decidir temas de carácter metropolitano, no existen espacios para la negociación. Un ejemplo concreto es la forma como se amplía la red de Metro: mientras en las comunas más ricas se hace de manera subterránea, respetando los espacios ya existentes y ofreciendo en la mayoría de los casos espacios públicos de alto estándar, en las comunas más pobres se utiliza infraestructura en superficie, la que muchas veces genera espacios públicos precarios, dividiendo comunas como verdaderas cicatrices urbanas.

La situación es bastante compleja, ya que cualquier avance democrático en las comunas populares no podría cambiar la correlación de fuerzas entre los municipios que componen el AMS. Sin duda que los procesos de democratización comunal podrían tener muchos beneficios: mayor legitimidad institucional, más transparencia, mejor distribución del presupuesto y más pertenencia de la ciudadanía hacia sus territorios. Sin embargo, es necesario identificar los límites de la participación comunal en el contexto actual, en el que la desigualdad entre comunas, las lógicas de dependencia y la falta de planificación urbana y territorial al momento de producir el espacio metropolitano responden al tipo de Estado, en el que los cambios locales serán siempre insuficientes para generar transformaciones estructurales. Existe literatura donde se profundiza respecto a este punto:

Una democracia territorial de proximidad, regionallocal, fuerte, podría ser un contrapeso importante y un mecanismo de participación democrática en los ámbitos globales. Pero sería muy ingenuo idealizar la actual democracia local y regional. Es cierto que tiene a su favor un conjunto de factores suficientemente reconocidos como son: a) la proximidad de la población a la gestión; b) la mayor capacidad de integrar las políticas 
públicas; c) la representatividad inmediata y directa de los gobiernos locales; d) la cultura cívica que considera iguales a todos los ciudadanos; e) la conciencia de identidad que los actuales procesos globalizadores han reforzado, como afirmación frente a la homogeneización. Pero hay otros factores de signo contrario que reducen y hasta suprimen los anteriores, como: a) los impactos sobre el territorio de decisiones económicas y políticas exteriores sobre las cuales los gobiernos locales y los actores de la sociedad civil tienen escasa o nula influencia y que tienen en cambio importantes efectos sociales y ambientales; $b$ ) la confusión, superposición y, muchas veces, escasa cooperación y poca transparencia de las administraciones públicas actuantes sobre el mismo territorio; c) la relativa debilidad legal y financiera en el marco regional metropolitano, de los gobiernos locales, que les impide jugar el rol integrador para el cual están más capacitados; d) la no adecuación entre las estructuras políticas representativas y las dinámicas sociales del territorio; e) la existencia de colectivos de población que no tienen reconocido el estatus de ciudadano y que por su misma existencia niegan uno de los valores esenciales de la ciudad: la igualdad en el espacio público y en el espacio de las libertades urbanas. (Borja, 2013).

Si ni siquiera la autoridad máxima de estos territorios tiene algún poder negociador frente a sus pares y estructuras superiores, entonces ¿cuál es la incidencia que tendría la ciudadanía respecto de la conformación del espacio metropolitano? La participación y consulta -aunque esta fuera vinculante- de los habitantes sería entonces una mera ficción al momento de poder generar mayores niveles de autonomía comunal e incidencia en los procesos de producción del territorio. Las lógicas de dependencia de los municipios estarían directamente condicionadas por el diseño y la implementación del Estado subsidiario, siendo la piedra de tope para una producción democrática del territorio metropolitano. 


\section{Lógicas de funcionamiento institucional: expectativas y realidades}

Las pretensiones del Estado subsidiario por propender al máximo desarrollo material y cultural de los ciudadanos tienen resultados bastante cuestionables. En el nivel territorial el nuevo rol estatal permitiría nuevas atribuciones a las comunas, las que podrían asumir las tareas que históricamente habían recaído en el Estado, tales como salud y educación. En el discurso suena bastante bien: "darles más poder a las comunas"; sin embargo, en la práctica, lo que ha ocurrido es que la mayoría de las comunas de la AMS no han tenido las posibilidades de hacerse cargo de estas responsabilidades de manera satisfactoria. El Estado ha transferido responsabilidades a las comunas sin entregar los recursos necesarios para la satisfacción de necesidades básicas.

El funcionamiento institucional del Estado subsidiario y su relación con los territorios tiene por un lado un relato y, por otro, efectos concretos en los diferentes espacios locales. Las expectativas están vinculadas entonces a este discurso que propone un espacio de realización de las personas de forma individual, generando las condiciones para que estas puedan desenvolverse sin los obstáculos estatales en su máxima expresión. Las realidades son los efectos concretos que el actual diseño institucional ha generado, lógicas de dependencia, desigualdades brutales entre municipios e ineficiencia de la mayoría de los gobiernos municipales para proveer derechos fundamentales. La libertad no es comprendida como un condición de dignidad mínima para que las personas se desenvuelvan, sino como la ausencia de la planificación política y urbana, con un predominio de las leyes del mercado al servicio de la acumulación de capital.

¿Qué condiciones de vida ha generado el Estado subsidiario en nuestro territorio? Para responder a esta pregunta se recurrirá a información estadística que sea transversal a todas las comunas de la AMS, y que, por lo tanto, pueda hacerlas comparables entre sí. Generalmente los indicadores de calidad de vida son de 
carácter nacional y con un fuerte sesgo financiero; para este caso necesitaremos indicadores que sean de carácter comunal y con un diseño multidimensional, permitiéndonos comprender el espacio urbano con mayor complejidad.

El indicador utilizado será el Índice de Calidad de Vida Urbana (ICVU), desarrollado por el Instituto de Estudios Urbanos y Territoriales (IEUT) UC y la Cámara Chilena de la Construcción (CChC), siendo el académico Arturo Orellana coordinador del equipo responsable (Instituto de Estudios Urbanos y Territoriales UC, 2015). El ICVU se basa en seis ámbitos que representan dimensiones de la calidad de vida urbana: Condición laboral; Ambiente de negocios; Condiciones socioculturales; Conectividad y movilidad; Salud y medio ambiente; Vivienda y entorno. Cada una de estas dimensiones obtendrá una puntuación de 0 a 100, sobre la base de variables estadísticas relacionadas. Finalmente, los indicadores por dimensión serán promediados de manera ponderada -cada dimensión no pesa un sexto, su participación en el porcentaje total fue determinado por una mesa de expertos que determinó su respectivo porcentaje- para obtener un indicador total que los integre a todos.

No deberían resultar novedosos los datos que este trabajo arroja. Por un lado, las 5 primeras comunas -Las Condes, Vitacura, Providencia, Lo Barnechea, La Reina- de la AMS tienen un ICVU promedio de 70,12. En el otro extremo las cinco últimas comunas -Conchalí, La Granja, Pedro Aguirre Cerda, La Pintana, San Ramón- tienen un ICVU promedio de 32,96, es decir, una brecha de 37,16. Las condiciones de vida de las comunas más acomodadas superan en más del doble a las comunas de los sectores populares. Podemos ver la existencia de dos ciudades en la AMS; por un lado un Santiago que se posiciona en el nivel de ciudades de países desarrollados, y, por otro, un Santiago totalmente excluido de estos beneficios. La diferencia en la calidad de vida en las diferentes comunas del AMS demuestra el fracaso administrativo de la subsidiaridad como modelo de desarrollo neoliberal. Las políticas focalizadas y la ausencia del Estado en 
la planificación del territorio metropolitano son formas como la subsidiariedad opera en el territorio.

Vemos entonces un desajuste entre las expectativas que el Estado subsidiario quiere generar y las realidades finalmente producidas. La arquitectura institucional propuesta produce un amarre a la real expresión democrática de los territorios, en la perspectiva de transferir poder a los espacios locales con visiones de incidencia en los procesos de construcción social. La construcción de una ciudad democrática, por tanto, no es un proceso que se pueda desarrollar de manera profunda en el escenario actual; sin embargo, las luchas por la democratización local serían una estrategia que podría poner en tensión el actual diseño social en cuanto a poder evidenciar sus limitaciones. El empoderamiento territorial, si bien hoy tiene espacios bastante estrechos en los cuales moverse, podría poner de manifiesto las contradicciones del actual modelo, en la perspectiva de buscar nuevas formas de planificación y gobernanza urbana que cuestionen las actuales lógicas de dependencia.

\section{Conclusiones}

A 25 años de la instauración del régimen democrático en Chile y luego de describir sus formas de relación tanto con los territorios como con la ciudadanía, el escenario político se enfrenta a una serie de preguntas: ¿qué posibilidades de democratización local existen en el marco del Estado subsidiario? ¿Cuáles son los límites de la democratización local que establece el Estado subsidiario? O, ¿cómo contempla la democratización local procesos de democratización metropolitana? Si bien existe una necesidad de responder estas preguntas, lo lógico será decir que ellas están en un proceso de reflexión en el escenario actual. El sistema político se enfrenta por lo mismo a una crisis de representatividad y, por ende, se cuestiona si sus intereses son públicos o privados. La discusión ha dejado de manifiesto que la formulación Estado subsidiario, democracia protegida y políticas de focalización es una 
ejecución de radicalismo conservador en pensar y planificar el territorio. El despotismo ilustrado de mediados del siglo XVIII tenía como principio: "La revolución con el pueblo... pero sin el pueblo", tal como lo entiende la subsidiariedad. Para este argumento político teórico diremos que, desde la territorialidad como consecuencia de la contradicción histórica del desarrollo de clases-, se debe accionar primero un pensar para luego planificar la sustentabilidad de un Estado de Derecho. Los formatos de desarrollo hasta la fecha son desde arriba hacia abajo, es decir, la institucionalidad diseña, planifica y ejecuta. La opción de este documento será una forma de organización coordinada entre la institucionalidad y los territorios, en la cual la comunicación opera como mecanismo que busca definir el contenido informativo de cada componente: territorio e institucionalidad.

A modo de conclusión, surgen algunos temas de gran relevancia en el marco de la discusión del tipo de Estado que queremos, así también como del desarrollo y planificación urbana y territorial. El Estado subsidiario se ha caracterizado por una planificación débil. El rol planificador del Estado ha sido fuertemente cuestionado por las posiciones neoliberales, acusando intromisión indebida y un atentado a la libertad. El Estado subsidiario se ha limitado a poner reglas de juego, sin tener un rol activo en la economía y la planificación del tipo de sociedad que queremos construir: ha sido un Estado en función de la administración del sistema neoliberal. La tesis presentada en este documento, así como la información estadística expuesta da cuenta de la necesidad de pensar el rol del Estado en una sociedad comprometida con los derechos sociales y, por lo tanto, con la igualdad de oportunidades. Las desigualdades entre las comunas no se resolverán con reformas cosméticas o mayor incorporación de las comunidades a la toma de decisiones comunales; estas deben abordase en una escala estatal y metropolitana.

Otro tema vinculado con el tipo de Estado que queremos es el rol que debería tener la planificación urbana y territorial en la producción de nuestras ciudades. Las ciudades o áreas metro- 
politanas actuales muchas veces no coinciden con las divisiones político-administrativas tradicionales, pensándose de manera fragmentada. El todo es mucho más que suma de las partes en la AMS; este territorio debe entenderse como una totalidad, teniendo una visión de ciudad y por lo tanto sistémica. Esto determinará si los procesos son capaces de producir una ciudad a la escala territorial de región metropolitana o crearán una amalgama de situaciones urbanas contradictorias, desiguales, poco sostenibles y de casi imposible gobierno (Borja, 2013).

La actual situación da cuenta de los límites de nuestra institucionalidad, en la medida en que no cuenta con los instrumentos necesarios para generar planes y estrategias, con el fin de abordar la planificación del territorio. La actual división municipal es abstracta, la conformación de la mayoría de las comunas no responde a criterios históricos, culturales o territoriales. Se deben generar cambios institucionales que permitan entender el Área Metropolitana de Santiago como un todo, con sus respectivas autoridades, capacitadas para tomar decisiones y con los instrumentos necesarios para planificar nuestro territorio. Avanzar en esta dirección es hacer un cuestionamiento de fondo a nuestra institucionalidad y la forma como entendemos y operamos en el territorio, es un cuestionamiento al rol que ha tomado en los últimos 30 años el Estado, por su carácter subsidiario.

Lo que es claro -en su dimensión política- es que no existen posibilidades de una democratización territorial profunda en el marco del Estado subsidiario, comprendiendo esta democratización como una transferencia de poder a los territorios y sus representantes, teniendo las atribuciones para incidir no solamente en la producción de los espacios municipales, sino también en la producción del territorio metropolitano y en las formas de reproducción social. Existe, por lo tanto, una contradicción en el diseño del Estado subsidiario y el fortalecimiento político, económico y social de manera equitativa de las comunas, ya que la ausencia del Estado en la planificación política y urbana acentúa las diferencias entre las comunas, las que son mantenidas y resaltadas por 
las lógicas mercantiles. Por esto, la democratización radical de los territorios es un proceso que debe considerar la democratización coordinada del Estado con los territorios. La tensión que vive el AMS desde la desigualdad territorial es una proyección del Estado subsidiario, que dedujo que a mayor nivel de desigualdad aumentaría una relación de competencia entre los espacios locales, hipótesis implementada desde la violencia política de los sectores conservadores del país. Dicho esto y luego de los datos arrojados por ICVU, podemos enfatizar que existe una necesidad urgente de un Estado moderno, capaz de incentivar la autonomía de los espacios locales, lo que no implica exclusivamente transferir responsabilidades, sino también que los espacios locales pueden participar en la apropiación del gasto social. Para esto, la toma de decisiones de los sectores populares debe ser identificada como una necesidad democrática para el desarrollo equitativo al interior de una ciudad.

\section{Referencias}

Borja, J. (2013). Revolución urbana y derechos ciudadanos. Madrid: Alianza Editorial.

Bourdieu, P. (2000). Poder, derecho y clases sociales. Bilbao: Desclée de Brouwer.

Constitución Política de la República de Chile. Diario Oficial de la República de Chile, Santiago, 24 de octubre de 1980.

Faletto, E. (2007). Dimensiones sociales, políticas y cultura del desarrollo. Santiago, Chile: Catalonia.

Finot, I. (2002). Descentralización y participación en América Latina: Una mirada desde la economía. Cepal, 78, 139-149.

Finot, I. (2005). Descentralización, transferencias territoriales y desarrollo local. Cepal, 86, 29-46.

Guzmán, J. (1982). El sentido de la transición. Realidad, 38, 3-21.

Hegel, G. (2009). Filosofía del Derecho. Buenos Aires: Editorial Claridad.

Instituto de Estudio Urbanos y Territoriales UC (2015). Índice de Calidad de Vida Urbana (ICVU). Recuperado el 29 de marzo 2016 de: http://www.ieut.cl/component/zoo/item/indice-de-calidad-de-vida-urbana-icvu 
Lefebvre, H. (1968). El derecho a la ciudad. Barcelona: Ediciones Península.

Lefebvre, H. (1974). La producción del espacio. Papers: revista de sociología, 3, 219-229.

Lukács, G. (2009). Historia y conciencia de clase. Estudios de dialéctica marxista. Buenos Aires: Ediciones RyR.

Ley $N^{\circ}$ 18.962. Ley orgánica constitucional de enseñanza. Diario Oficial de la República de Chile, Santiago, 10 de marzo de 1990.

Luhmann, N. (2005). El derecho de la sociedad. México DF: Herder.

Magnaghi, A. (2011). El proyecto local: hacia una conciencia de lugar. Barcelona: Universitat de Catalunya.

Orellana, A. (2009). La gobernabilidad metropolitana de Santiago: la dispar relación de poder de los municipios. EURE, 38(115), 101-120.

Offe, C. (1988). Algunas contradicciones del moderno Estado del Bienestar. En Contradicciones en el Estado del Bienestar, 72-104. Madrid: Alianza Editorial.

Pérez, C. (2010). Sobre Hegel. Santiago: LOM Ediciones.

Rawls, J. (2012). Teoría de la Justicia. México DF: Fondo de Cultura Económica.

Racsynki, D. (1995). Focalización de programas sociales: lecciones de la experiencia chilena. En J. Vial, D. Racsynki y C. Pizarro. Políticas Económicas y Sociales en el Chile Democrático, 217-255. Santiago, Chile: CIEPLAN.

República de Chile. Actas oficiales de la comisión constituyente, sesión 10a. Santiago, 25 de octubre de 1973.

Sassen, S. (1999). La ciudad global: Nueva York, Londres, Tokio. Buenos Aires: Eudeba.

Subsecretaría de Desarrollo Regional y Administrativo. (2009). Fondo Común Municipal. Recuperado el 29 de marzo 2016 de: http://www.subdere.gov.cl/programas/división-municipalidades/fondo-común-municipal-fcm

Wilke, H. (2006). La transformación de la democracia como modelo de orientación de las sociedades complejas. Revista de Estudios Públicos, 106, 179-201. 